\title{
Spontaneous Splenic Rupture: A Case Report
}

\author{
Chehboun A*, Ait Chtouk M, Tadsaoui S, Boutakioute B, Ouali Idrissi M, Cherif Idrissi Ganouni N
}

Radiology department, Arrazi Hospital, Mohammed VI university hospital, Marrakech, Morocco

DOI: $10.36347 /$ sjmcr.2020.v08i11.014

| Received: 16.10 .2020 | Accepted: 29.10.2020 | Published: 23.11 .2020

*Corresponding author: Chehboun A

\section{Abstract}

Spontaneous splenic rupture is a rare life-threatening condition, it's occurrence with no history of underlying splenic disease makes it even extremely rare. We report a case of a 26 year-old male who presented with acute left sided abdominal pain with no history of trauma; a CT scan was performed individualizing an abundant intra peritoneal free fluid associated with multiples splenic lacerations and hematomas. Conservative management was carried with a good evolution.

Keywords: Spontaneous Rupture.

Copyright $\left({ }^{\circ} 2020\right.$ The Author(s): This is an open-access article distributed under the terms of the Creative Commons Attribution 4.0 International License (CC BY-NC 4.0) which permits unrestricted use, distribution, and reproduction in any medium for non-commercial use provided the original author and source are credited.

\section{INTRODUCTION}

The majority of splenic ruptures are secondary to trauma; spontaneous rupture is rare, occurring on multiples underlying pathologies. We report a case of a young male with no history of trauma or splenic disease who presented a splenic rupture with free peritoneal fluid.

\section{CASE RePORT}

A 26 year-old man, with no medical history who presented to the emergency department with acute left sided, severe abdominal pain.

On initial examination, the patient was pale, his pulse was $100 \mathrm{bpm}$, his blood pressure was $11 / 7$ cmHg. Abdominal examination showed general abdominal sensitivity accentuated on left flank the blood tests showed an hemoglobin level of $8.5 \mathrm{~g} / \mathrm{dl}$.

After initial fluid administration, the patient underwent a CT scan which showed a spontaneous dense free abdominal fluid (figure 1), on injected series, we noticed an heterogeneous spleen, with multiples lacerations and hematomas (figure 2), on MIP reconstructions, there were no vascular rupture (figure 3).

A conservative approach was conducted consisting of close monitoring, hydration and red blood cells transfusion. Afterwards, the patient remained haemodynamically stable, the splenectomy was not indicated.

\section{DISCUSSION}

Spontaneous splenic rupture is a rare but potentially life-threatening entity. It can be due to neoplastic, infectious, haematological, inflammatory and metabolic causes. An iatrogenic or an idiopathic aetiology should also be considered [1].

There is a variation in symptom manifestation in patients with splenic rupture. The presence of abdominal pain in splenic rupture has been frequently reported abdominal pain, tenderness in the epigastrium and discomfort in the left upper quadrant may be seen in patients who have experienced minor injury. In larger splenic injuries, signs of hypovolemic shock were a common presentation [2].

A CT scan is often essential to make the diagnosis and grade the splenic injury, although an ultrasound scan may be clinically useful. The most common finding on CT is splenomegaly with splenic lacerations and intraperitoneal or subcapsular bleeding [3].

Therapeutic attitude depends essentially on the clinical situation guiding the surgical decision of splenectomy, patients may be managed conservatively even with high grade splenic injuries on CT scan if they are haemodynamically stable [4] which was the case for our patient the whom a conservative approach was carried even with important splenic lesions. 


\section{Conclusion}

Spontaneous splenic rupture is a rare yet potentially life threatening condition, thus, it should be considered as a differential diagnosis in all patients presenting with upper left acute abdominal pain even with no trauma history.

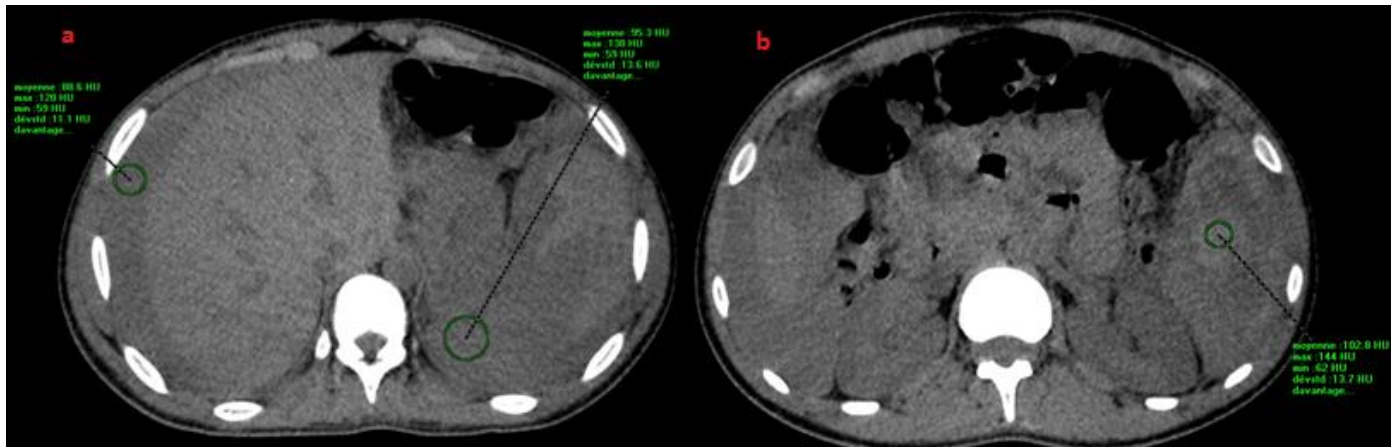

Fig-1: Axial CT section without contrast showing spontaneous dense free abdominal fluid (80HU) (a) with splenic hematoma (b)

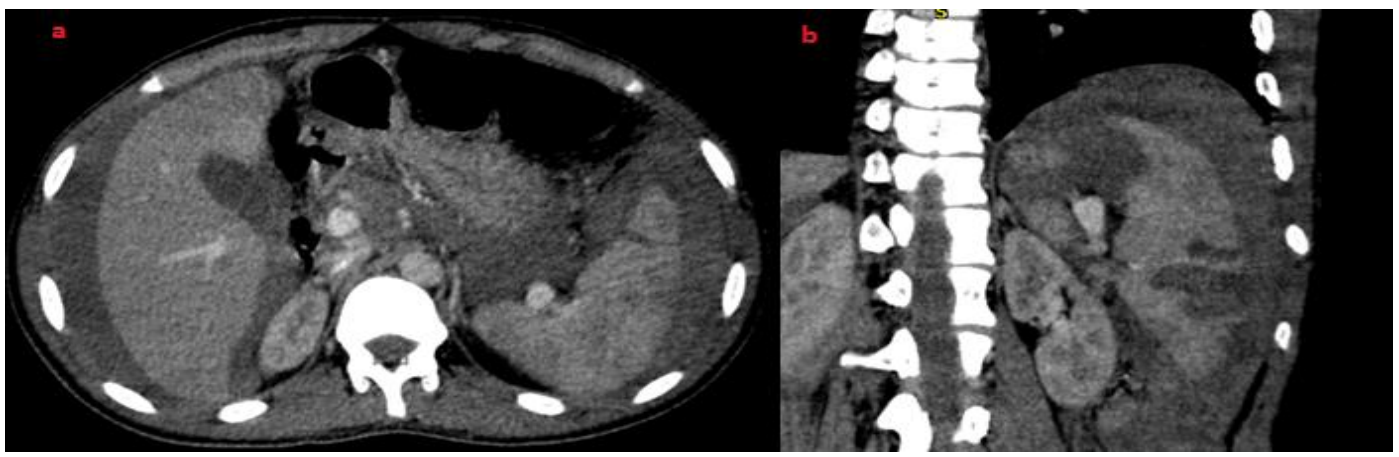

Fig-2: Axial (a) and coronal (b) enhanced CT sections showing heterogenous spleen with lacerations and hematomas

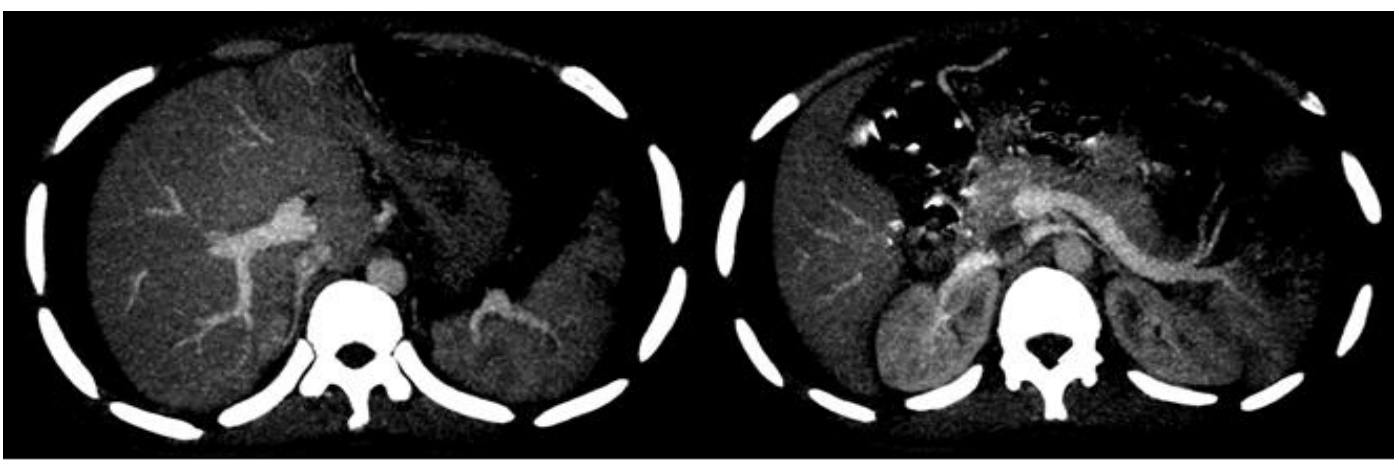

Fig-3: Axial MIP CT reconstructions showing integrity of spleen vessels

\section{REFERENCES}

1. Dunphy L, Abbas SH, Patel A. Spontaneous splenic rupture: a rare first presentation of diffuse large B cell lymphoma BMJ Case Reports CP. 2019; 12:e231101.

2. Kaniappan K, Lim CTS and Chin PW. Nontraumatic splenic rupture - a rare first presentation of diffuse large B-cell lymphoma and a review of the literature. 2018; BMC Cancer 18, 779 https://doi.org/10.1186/s12885-018-4702-1
3. Foreman BH, Mackler L, Malloy ED. Can we prevent splenic rupture for patients with infectious mononucleosis? J Fam Pract. 2005;54:547-48

4. Weaver H, Kumar V, Spencer K, Maatouk M and Malik S. Spontaneous splenic rupture: A rare lifethreatening condition; Diagnosed early and managed successfully. The American journal of case reports. 2013; 14, 13-15. https://doi.org/10.12659/AJCR.883739. 